\title{
Effects of enalapril on myocardial noradrenaline overflow during exercise in patients with chronic
} heart failure

\author{
I P MULLIGAN, A G FRASER, M J LEWIS, * A H HENDERSON \\ From the Departments of Cardiology and $\star$ Pharmacology, University of Wales College of Medicine, Cardiff
}

SUMMARY The effects of the angiotensin converting enzyme inhibitor enalapril on myocardial sympathetic tone, as represented by noradrenaline overflow, were studied in 14 men with congestive heart failure (mean ejection fraction $20 \%$ ) in a double blind crossover comparison with placebo. Arterial and coronary sinus catecholamine concentrations and oxygen content, and coronary sinus blood flow, were measured at rest and during peak symptom limited upright exercise on a bicycle ergometer. There were no significant changes four hours after the first dose of enalapril, but after six weeks of treatment $(10-20 \mathrm{mg} /$ day) enalapril reduced myocardial overflow of noradrenaline at peak exercise. The external workload (exercise duration) increased from baseline values after both placebo and enalapril, and there was no difference between placebo and enalapril at six weeks. Heart work, however, was lower after enalapril: stroke work index was reduced at rest and the double product was lower at peak exercise. The reduction in maximal myocardial oxygen consumption after enalapril did not reach statistical significance. Coronary sinus adrenaline concentrations after enalapril and after placebo were not significantly different.

The long term reduction of myocardial sympathetic activity on exercise may represent a significant benefit from angiotensin converting enzyme inhibition in heart failure and may reflect a reduced cardiac workload.

In congestive heart failure the sympathetic drive is increased, ${ }^{1}$ as manifest by raised blood concentrations of noradrenaline $e^{2}$ in association with reduced myocardial noradrenaline content and down regulation of $\beta_{1}$ receptors. ${ }^{3}$ Noradrenaline concentrations in the coronary sinus are also raised at rest, suggesting an increased sympathetic drive to the heart in chronic heart failure. ${ }^{45}$

Angiotensin converting enzyme inhibitors have proved beneficial in the treatment of chronic heart failure..$^{6-10}$ There is also evidence that they reduce raised systemic concentrations of noradrenaline ${ }^{11} 12$ and that they may reduce the incidence of ventricular arrhythmias. ${ }^{113}$ It is possible that some of their beneficial effects may be mediated through actions on myocardial sympathetic stimulation.

We investigated the short term and long term

Requests for reprints to Dr A G Fraser, Department of Cardiology, University of Wales College of Medicine, Heath Park, Cardiff CF4 4XN.

Accepted for publication 27 July 1988 effects of the angiotensin converting enzyme inhibitor enalapril on arterial and coronary sinus noradrenaline concentrations at rest and on exercise in patients with heart failure.

\section{Patients and methods}

We studied 14 men aged 30-69 (mean (SD) 50.9 (11.5)); 11 had coronary heart disease without evidence of effort related myocardial ischaemia and three had dilated cardiomyopathy. Nine were in New York Heart Association class II and five were in class III. Radionuclide ejection fractions on entry to the study ranged from $10 \%$ to $39 \%$ (mean (SD) 20 $(8) \%)$. All patients were treated with constant doses of digoxin $(0.25(0.09) \mathrm{mg} /$ day $)$ and diuretics (frusemide $114(123) \mathrm{mg}, \mathrm{n}=14$; amiloride 8.5 (2.4) $\mathrm{mg} /$ day, $\mathrm{n}=10$ ) throughout the trial.

All the patients gave written informed consent and completed a 12 week double blind placebo controlled randomised crossover trial. All patients were studied five times, during three separate study days at the 
beginning and end of two six week periods. They were studied first on entry to the trial (baseline data), and thereafter they were randomised to receive enalapril $10 \mathrm{mg}$ orally or matched placebo. Four hours later we measured the short term data. Treatment was continued, and increased after two weeks to enalapril $20 \mathrm{mg} /$ day or placebo two tablets per day, if there were no symptoms suggestive of hypotension or other unwanted effects. After six weeks, patients were studied again four hours after the last dose of enalapril or placebo (long term data), and then given the first dose of the alternative treatment. The protocol was repeated, with short term data being obtained four hours after this dose, and long term data six weeks later at the end of the study and four hours after the last dose. During long term treatment 12 patients received enalapril $20 \mathrm{mg} /$ day and two patients took $10 \mathrm{mg} /$ day.

On each occasion patients completed a maximal symptom limited exercise test on a bicycle ergometer. They had at least two training tests before entry into the study, and the exercise protocol was uniform. The initial workload of $25 \mathrm{~W}$ was increased by $25 \mathrm{~W}$ every three minutes until exercise was limited by dyspnoea or fatigue. Recordings were made in the same sequence, first at rest (sitting on the bicycle) and then at peak exercise.

Measurements of haemodynamic function and blood samples for estimation of oxygen saturation and adrenaline and noradrenaline concentrations were obtained from a cannula in the radial artery, a Swan Ganz catheter in the pulmonary artery, and a Baim catheter ${ }^{14}$ in the coronary sinus; the proximal thermistor and sampling port of the Baim catheter were placed about $2 \mathrm{~cm}$ beyond the coronary sinus orifice. A satisfactory coronary sinus catheter position, confirmed by the injection of $5 \mathrm{ml}$ of low osmolar contrast medium, was obtained in $75 \%$ of tests. During the measurement of cardiac output we confirmed that in these patients the recordings of the coronary sinus thermistor were not altered by the injection of an ice cold bolus of $5 \%$ dextrose into a central vein-this showed that there was no evidence of reflux from the right atrium into this portion of the coronary sinus at rest or on exercise. ${ }^{15}$ Previous radiographic studies showed that such catheters were stable during bicycle exercise ${ }^{16}$ After insertion of the catheters, the patients rested for at least one hour before the first measurements.

Blood flow in the coronary sinus was measured with an Elecath Baim coronary flow system (Electro Catheter Corporation) during an infusion of $5 \%$ dextrose at $40 \mathrm{ml} /$ minute at room temperature. Plasma catecholamine concentrations were estimated by high pressure liquid chromatography with electrochemical detection. ${ }^{17}$ Myocardial overflow of adrenaline or noradrenaline was calculated as the product of the difference between aortic concentrations of adrenaline or noradrenaline and coronary sinus concentrations, and the coronary sinus plasma flow, which was calculated as: coronary sinus blood flow $\times(1$ - venous haematocrit). The haematocrit for this last calculation was measured in a venous blood sample taken at rest within 24 hours of the start of each study day. Total body oxygen consumption was calculated as the product of systemic arteriovenous oxygen content difference (in $\mathrm{ml} / \mathrm{l}$ ) and cardiac output (the mean of three separate thermodilution curves) divided by body weight. ${ }^{18}$ Myocardial oxygen consumption was calculated as the product of the difference between the aortic and coronary sinus oxygen contents and coronary sinus blood flow. Stroke work was calculated as the product of stroke index (cardiac output divided by heart rate, per $\mathrm{m}^{2}$ body surface area) and the difference between the mean systemic arterial and the mean pulmonary capillary wedge pressures.

The results were analysed first according to the method of Hills and Armitage for a crossover trial. ${ }^{19}$ There were no significant period or carry over effects on the long term data reported in this study. Baseline data were incomplete in six men because of initial inexperience in coronary sinus catheterisation, but long term treatment data were obtained in most subjects. We therefore report the results of paired $t$ tests to compare the long term effects of enalapril with those of placebo. We also used paired $t$ tests to compare the long term effects of enalapril or placebo with baseline values.

Short term effects were compared with control data obtained according to the randomised treatment order either at baseline or after the last dose of placebo, but in each case just before the first dose of enalapril.

We used Spearman's rank correlation method. A value of $p<0.05$ was regarded as significant for two tailed tests.

\section{Results}

The effects of enalapril on haemodynamic measurements and circulating concentrations of hormones have been reported in detail elsewhere. ${ }^{20}$ Table 1 summarises the haemodynamic effects of long term treatment. We confirmed that enalapril lowers systemic vascular resistance and blood pressure, and it also lowered pulmonary capillary wedge pressure at rest. Symptoms were significantly improved after treatment for six weeks, although the exercise tolerance was unchanged. Enalapril increased plasma renin activity and reduced aldosterone concentrations, as expected, but did not affect 
Table 1 Summary of systemic effects of enalapril during long term treatment

\begin{tabular}{|c|c|c|c|c|c|c|c|c|}
\hline & \multicolumn{2}{|l|}{ Baseline } & \multicolumn{2}{|l|}{ Placebo } & \multicolumn{2}{|l|}{ Enalapril } & \multicolumn{2}{|c|}{ Percentage difference } \\
\hline & Rest & Exercise & Rest & Exercise & Rest & Exercise & Rest & Exercise \\
\hline \multirow{4}{*}{$\begin{array}{l}\text { Heart rate (beats/min) } \\
\text { Mean arterial blood pressure } \\
\text { (mm Hg) } \\
\text { System vascular resistance } \\
\text { (dyne.s.cm }{ }^{-5} \text { ) } \\
\text { Pulmonary capillary wedge } \\
\text { pressure (mm } \mathrm{Hg} \text { ) } \\
\text { Cardiac index }\left(\mathrm{l} / \mathrm{min} / \mathrm{m}^{2}\right)\end{array}$} & $83(15)$ & $114(22)$ & $88(14)$ & $128(34)$ & $94(20)$ & $124(26)$ & +6.3 & $-2 \cdot 7$ \\
\hline & $90(16)$ & $99(15)$ & $94(14)$ & $103(10)$ & $76(14)$ & $87(17)$ & $-19 \cdot 4^{\star}$ & $-15 \cdot 9 \star$ \\
\hline & $2189(1003)$ & 1178 & 2084 (319) & $1177(388)$ & $1756(341)$ & $1014(363)$ & $-15 \cdot 7^{\star}$ & -13.8 \\
\hline & $\begin{array}{l}11(8) \\
2.0(0.3)\end{array}$ & $\begin{array}{c}19(13) \\
4.0(1.5)\end{array}$ & $\begin{array}{c}13(11) \\
1.9(0.2)\end{array}$ & $\begin{array}{l}19(9) \\
4 \cdot 2(1.4)\end{array}$ & $\begin{array}{l}9(7) \\
1.9(0 \cdot 2)\end{array}$ & $\begin{array}{c}16(10) \\
4 \cdot 0(1 \cdot 2)\end{array}$ & $\begin{array}{c}-28 \cdot 3^{\star} \\
-3.6\end{array}$ & $\begin{array}{r}-14.6 \\
-6.0\end{array}$ \\
\hline
\end{tabular}

Results are mean (SD). Percentages refer to changes from placebo values during enalapril treatment. ${ }^{\star} \mathrm{p}<0.05 ; \mathrm{n}=14$.

systemic concentrations of adrenaline or noradrenaline.

Table 2 summarises the short term effects of enalapril on myocardial function. There were no significant changes in coronary sinus blood flow, myocardial oxygen consumption, or catecholamine concentrations in the coronary sinus, either at rest or at peak exercise. There were no short term alterations in the myocardial overflows of adrenaline and noradrenaline by enalapril, but there were very wide variations between patients. Negative values for overflow imply net myocardial uptake.

Six weeks of treatment with enalapril produced no significant change in exercise tolerance. The mean (SD) exercise duration was 578 (282) s, compared with 615 (288) s after six weeks of placebo; both figures were higher than baseline values $(538(282) \mathrm{s})$, but there were no significant differences between enalapril and placebo values. There was also little change in total body oxygen consumption, which was reduced by $18 \%$ at peak exercise (NS) after enalapril compared with placebo. However, heart work was reduced: the double product (systolic blood pressure $x$ heart rate) was $18.6 \%$ lower after enalapril than after placebo at rest $(p<0.05)$ and by $20.6 \%$ at peak exercise $(\mathbf{p}<0.05)$ (table 3$)$, and the stroke work index at rest was $22 \%$ lower after enalapril than after placebo ( $p<0.05$ ). Myocardial oxygen consumption was also lower after enalapril, by $10.5 \%$ at rest and $25.8 \%$ at peak exercise, but these changes were not statistically significant. Coronary sinus blood flow was $5.9 \%$ lower at rest and $16.1 \%$ lower at peak exercise (both NS); the difference in oxygen content between arterial and coronary sinus blood was $7 \cdot 2 \%$ lower at rest and $12.5 \%$ lower at peak exercise (both $\mathrm{p}<0.05)$.

Arterial noradrenaline concentrations were unaltered after six weeks' treatment with enalapril but noradrenaline concentrations in the coronary sinus were lower than after placebo by $17 \cdot 3 \%$ at rest (NS) and by $27.1 \%$ at peak exercise $(p<0.05)$ (table 3 ). Myocardial overflow of noradrenaline was $55 \%$ lower at rest (NS) and $88 \%$ lower at peak exercise $(p<0.05)$. It was also substantially lower after enalapril than at baseline, both at rest and on exercise.

The mean concentration of adrenaline in the coronary sinus and the myocardial overflow of adrenaline were higher at rest after enalapril that at baseline, burmyocardial adrenaline metabolism after long term treatment with enalapril was not significantly different from long term treatment with placebo. The negative values sometimes obtained may reflect transmyocardial metabolism of adrenaline or net uptake of adrenaline.

Myocardial oxygen consumption correlated well with double product $(\rho=+0.62, \mathrm{p}<0.001$, for 101 paired observations), and both correlated

Table 2 Comparison between myocardial function (mean (SD)) after short term treatment with enalapril and control data (baseline or placebo) ( $n=9$ unless otherwise indicated)

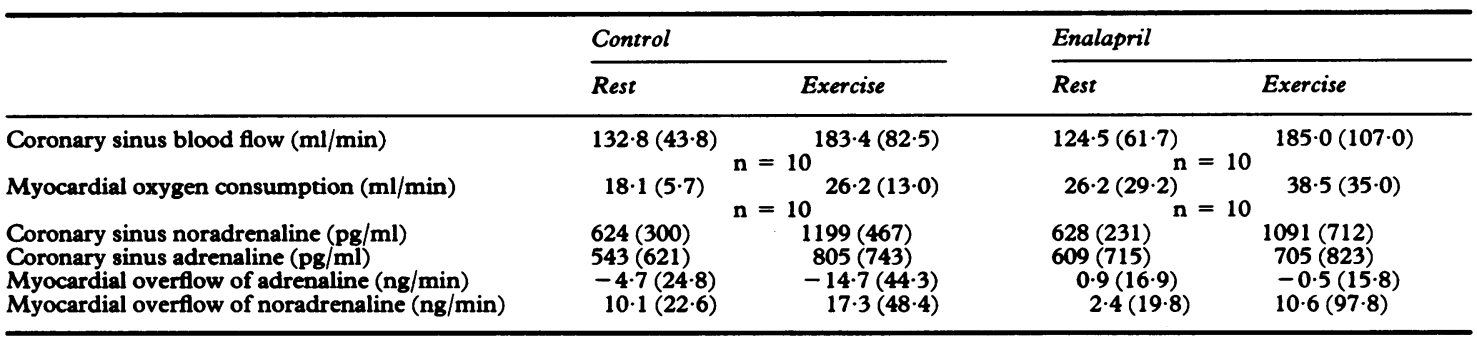


Table 3 Effects (mean (SD)) of long term treatment with enalapril and placebo on myocardial function

\begin{tabular}{|c|c|c|c|c|c|c|}
\hline & \multicolumn{2}{|l|}{ Baseline } & \multicolumn{2}{|l|}{ Enalapril } & \multicolumn{2}{|l|}{ Placebo } \\
\hline & Rest & Exercise & Rest & Exercise & Rest & Exercise \\
\hline $\begin{array}{l}\text { Coronary sinus blood flow (ml/min) } \\
\text { Coronary sinus } \mathrm{O}_{2} \text { saturation }(\%) \\
\text { Arterial-coronary sinus } \mathrm{O}_{2} \text { content } \\
\text { difference (ml/dl) } \\
\text { Myocardial oxygen consumption } \\
\quad \text { (ml/min) } \\
\text { Coronary sinus noradrenaline } \\
\text { (pg/ml) } \\
\text { Coronary sinus adrenaline (pg/ml) } \\
\text { Myocardial overflow of } \\
\text { noradrenaline (ng/min) } \\
\text { Myocardial overflow of adrenaline } \\
\text { (ng/min) } \\
\text { Stroke work index (ml.mm } \mathrm{Hg} / \mathrm{m}^{2} \text { ) } \\
\text { Double product (mm } \mathrm{Hg} \cdot \mathrm{min} \text { ) }\end{array}$ & $\begin{array}{l}118 \cdot 5(32 \cdot 9) \\
n=8 \\
34 \cdot 8(7 \cdot 4) \\
n=9 \\
12 \cdot 8(2 \cdot 7) \\
n=9 \\
16 \cdot 2(5 \cdot 7) \\
n=8 \\
672(385) \\
n=8 \\
240(364) \\
n=8 \\
19 \cdot 8(28 \cdot 3) \\
n=8 \\
-0 \cdot 8(50 \cdot 6) \\
n=8 \\
1895(622) \\
n=14 \\
10693(2364) \\
n=14\end{array}$ & $\begin{array}{l}162 \cdot 3(66 \cdot 8) \\
n=8 \\
30 \cdot 4(9 \cdot 1) \\
n=9 \\
14 \cdot 1(2 \cdot 9) \\
n=9 \\
24 \cdot 5(12 \cdot 5) \\
n=8 \\
1117(567) \\
n=8 \\
394(515) \\
n=8 \\
47 \cdot 5(70 \cdot 4) \\
n=8 \\
-4 \cdot 7(25 \cdot 3) \\
n=8 \\
2717(848) \\
n=14 \\
17.427(5817) \\
n=14\end{array}$ & $\begin{array}{l}133 \cdot 3(39 \cdot 3) \\
n=12 \\
33 \cdot 4(6 \cdot 8) \\
n=11 \\
12 \cdot 4(1 \cdot 4) \star \\
n=11 \\
16 \cdot 9(4 \cdot 9) \\
n=11 \\
930(464) \\
n=11 \\
888(896) \dagger \\
n=11 \\
9 \cdot 0(66 \cdot 5) \dagger \\
n=11 \\
17 \cdot 4(34 \cdot 3) \dagger \\
n=11 \\
1412(454) \star \\
n=14 \\
9799(2016) \star \\
n=14\end{array}$ & $\begin{array}{l}201 \cdot 3(80 \cdot 5) \\
n=12 \\
32 \cdot 7(9 \cdot 6)^{\star} \\
n=12 \\
12 \cdot 4(2 \cdot 4)^{\star} \\
n=12 \\
26 \cdot 1(12 \cdot 9) \\
n=12 \\
1491\left((647)^{\star}\right. \\
n=12 \\
890(907) \\
n=12 \\
10 \cdot 6(105 \cdot 8)^{\star} \dagger \\
n=12 \\
26 \cdot 4(90 \cdot 1) \\
n=12 \\
2336(1151) \\
n=14 \\
16903(5722)^{\star} \\
n=14\end{array}$ & $\begin{array}{l}141 \cdot 7(53 \cdot 0) \\
n=11 \\
31 \cdot 1(6 \cdot 5) \\
n=12 \\
13 \cdot 3(2 \cdot 0) \\
n=12 \\
18 \cdot 9(6 \cdot 7) \\
n=11 \\
1124(868) \\
n=12 \\
492(544) \\
n=12 \\
20 \cdot 2(75 \cdot 1) \\
n=12 \\
0 \cdot 1(23 \cdot 6) \\
n=12 \\
1806(502) \\
n=14 \\
12051(2985) \\
n=14\end{array}$ & $\begin{array}{l}239 \cdot 8(116) \\
n=11 \\
26 \cdot 4(6 \cdot 4) \dagger \\
n=12 \\
14 \cdot 2(2 \cdot 1) \\
n=12 \\
35 \cdot 2(18 \cdot 7) \\
n=11 \\
2044(1052) \\
n=12 \\
653(679) \\
n=12 \\
92 \cdot 5(133 \cdot 3) \\
n=12 \\
-4 \cdot 0(46 \cdot 7) \\
n=12 \\
2844(1080) \\
n=14 \\
21292(6576) \dagger \\
n=14\end{array}$ \\
\hline
\end{tabular}

${ }^{\star} \mathrm{p}<0.05$ for enalapril $v$ placebo.

$+\mathrm{p}<0.05$ for enalapril or placebo $v$ baseline.

weakly with myocardial noradrenaline overflow $(\rho=+0.30, \mathrm{p}<0.01$, and $\rho=+0.27, \mathrm{p}<0.05$, respectively).

\section{Discussion}

Patients with chronic heart failure have raised concentrations of noradrenaline in peripheral blood, ${ }^{2}$ reflecting increased sympathetic activity. On exercise, systemic noradrenaline concentrations increase, so that for any given external workload noradrenaline concentrations are higher in patients with heart failure than they are in normal individuals. ${ }^{21}$ Exercise in normal subjects also increases the concentration of noradrenaline in the coronary sinus more than in arterial blood. ${ }^{22}$ In patients with heart failure noradrenaline release into the coronary sinus is increased at rest, implying abnormally high sympathetic drive to the heart. ${ }^{53}$ We showed that with exercise there was a further increase in sympathetic stimulation to failing hearts.

In this study noradrenaline release from myocardial sympathetic neurones was not measured directly, but it was estimated from the calculated myocardial noradrenaline overflow. Previous studies showed that calculated overflow accurately reflects true release $\mathrm{e}^{24}$; the assumptions implicit in such calculations (for example that rates of noradrenaline reuptake are constant) are valid except at very much lower flow rates than any in the present study. ${ }^{25} \mathrm{It}$ is also unlikely that the results were influenced by changes in venous haematocrit on exercise. Although corrections for plasma flow were made by using a single haematocrit measurement taken at rest on each study day, the reduction in plasma volume on exercise is likely to have been as little as 4-7\% ${ }^{26}{ }^{27}$ Any consequent slight overestimation of catecholamine overflow on exercise would have affected both placebo and treatment data, and it is unlikely that this could have significantly influenced the results. Similarly, any reduction in coronary sinus oxygen saturation due to ischaemia would have affected both placebo and treatment data; however, there was no symptomatic or electrocardiographic evidence of exercise induced ischaemia in any of these patients.

The statistical data from this study were analysed by the methods of Hills and Armitage for a crossover trial. ${ }^{19}$ There were significant period effects influencing short term placebo data, and so the short term effects of enalapril (summarised in table 1) were studied with an analysis of variance of data from the first study day only. ${ }^{20} \mathrm{~A}$ full Hills-Armitage analysis was hampered by missing data caused by failed coronary sinus catheterisation on some occasions. However, a Hills-Armitage analysis of those variables for which full data were available, showed no period or order effects on long term results. The longer term effects were therefore studied by paired $t$ tests. We report in particular the comparisons between long term enalapril and long term placebo data, since this is the most important comparison in a crossover study, once carry over effects have been excluded. The standard deviations of several variables in this study are quite large, because of wide 
biological variability and comparatively small numbers of observations, so that although some changes (such as the reduction in peak myocardial oxygen consumption) were not statistically significant they may nevertheless be real and of clinical importance.

The short term effects of captopril, a combination of hydralazine and isosorbide dinitrate,$^{28}$ and the inotropic vasodilator MDL $17043^{29}$ on myocardial catecholamine overflow in congestive heart failure have been studied at rest. Captopril and MDL 10743 did not alter the differences between arterial and coronary sinus noradrenaline concentrations or overflow, but overflow was increased by the hydralazine and isosorbide dinitrate combination. In the present study, enalapril similarly had no short term effect on myocardial noradrenaline overflow, either at rest or on exercise.

We found that myocardial noradrenaline overflow at peak exercise in patients with congestive heart failure was much lower when they had taken enalapril for six weeks than when they had taken placebo. This occurred despite similar levels of exercise, as assessed by duration of exercise or by calculated total maximal oxygen consumption. The reductions in stroke work index at rest and in double product on exercise, together with a substantial (but not statistically significant) fall in calculated myocardial oxygen consumption on exercise, all imply a reduction in myocardial energy requirements on exercise after enalapril. The reduced overflow of noradrenaline may thus be a secondary effect of enalapril, reflecting a reduction in cardiac workload or improvement in cardiac efficiency at any given external workload. Alternatively, it may reflect a direct reduction of the sympathetic drive that is mediated via high concentrations of angiotensin II..$^{30} 31$

In congestive heart failure the normal increase in heart rate and blood pressure on tilting is blunted, because of decreased tonic inhibition of vasomotor centres by cardiac mechanoreceptors, and because of the impaired ability of the arterial baroreceptors to modulate sympathetic outflow. ${ }^{32}$ The lack of increase in heart rate in the present study, despite a fall in blood pressure, implies that there may have been some resetting of the baroreceptors. In a previous study with captopril the expected increase in heart rate on tilting did not occur, suggesting a parasympathetic abnormality. ${ }^{33}$

The effects reported in this study of enalapril on myocardial function show a mechanism by which angiotensin converting enzyme inhibition may produce a considerable benefit in heart failure. High plasma concentrations of noradrenaline at rest correlate with poor exercise capacity in heart failure ${ }^{34}$ and with mortality, ${ }^{35}$ and high levels of sympathetic activity may contribute to potentially dangerous arrhythmias in this condition. ${ }^{36} \mathrm{~A}$ therapeutic reduction in sympathetic drive to the heart may thus be beneficial.

We thank Merck Sharp and Dohme Limited for their support of this study.

\section{References}

1 Bristow MR. The adrenergic nervous system in heart failure. $N$ Engl J Med 1984;311:850-1.

2 Thomas JA, Marks BH. Plasma norepinephrine in congestive heart failure. Am J Cardiol 1978;41: 233-43.

3 Bristow MR, Ginsburg R, Minobe W, et al. Decreased catecholamine sensitivity and beta-adrenergic receptor density in failing human hearts. $N$ Engl $\mathrm{J} \mathrm{Med}$ 1982;307:205-11.

4 Swedberg K, Hjalmarson A, Holmberg S. Effects of work and acute beta-receptor blockade on myocardial noradrenaline release in congestive cardiomyopathy. Clin Cardiol 1979;2:424-30.

5 Swedberg K, Viquerat C, Rouleau JL, et al. Comparison of myocardial catecholamine balance in chronic congestive heart failure and in angina pectoris without failure. Am J Cardiol 1984;54:783-6.

6 Packer M. Vasodilator and inotropic therapy for severe chronic heart failure: passion and skepticism. $\mathrm{J} \mathrm{Am}$ Coll Cardiol 1983;2:841-52.

7 Edwards CRW, Padfield PL. Angiotensin-converting enzyme inhibitors: past, present and bright future. Lancet 1985;i:30-4.

8 Kramer BL, Massie BM, Topic RN. Controlled trial of captopril in chronic heart failure: a rest and exercise hemodynamic study. Circulation 1983;67:807-16.

9 Captopril Multicenter Research Group. A placebo controlled trial of captopril in refractory chronic congestive failure. J Am Coll Cardiol 1983;2:755-63.

10 The CONSENSUS Trial Study Group. Effects of enalapril on mortality in severe congestive heart failure. $N$ Engl J Med 1987;316:1429-35.

11 Cleland JGF, Dargie HJ, Ball SG, et al. Effects of enalapril in heart failure: a double blind study of effects on exercise performance, renal function, hormones, and metabolic state. Br Heart J 1985;54: 305-12.

12 Creager MA, Halperin JL, Bernard DB, et al. Acute regional circulatory and renal hemodynamic effects of converting-enzyme inhibition in patients with congestive heart failure. Circulation 1981;64:483-9.

13 Cleland JGF, Dargie HJ, Robertson JIS, Ball SG, Hodsman GP. The use of captopril in the management of cardiac failure. Scott Med J 1984;29:129-30.

14 Baim DS, Rothman MT, Harrison DC. Improved catheter for regional coronary sinus flow and metabolic studies. Am J Cardiol 1980;46:997-1000.

15 Mathey DG, Chatterjee K, Tyberg JV, Lekven J, Brundage G, Parmley WW. Coronary sinus reflux: a source of error in measurement of thermodilution coronary sinus flow. Circulation 1978;57:778-86. 
16 Magorien RD, Leier CV, Kolibash AJ, Barbush TJ, Unverferth DV. Beneficial effects of nifedipine on rest and exercise myocardial energetics in patients with congestive heart failure. Circulation 1984:70:884-90.

17 Eriksson B-M, Persson B-A. Determination of catecholamines in rat heart tissue and plasma samples by liquid chromatography with electrochemical detection. J Chromatogr 1982;228:143-54.

18 Rubin SA, Siemienczuk D, Nathan MD, Prause J, Swan HJC. Accuracy of cardiac output, oxygen uptake and arteriovenous oxygen difference at rest, during exercise, and after vasodilator therapy in patients with severe, chronic heart failure. Am J Cardiol 1982;50:973-8.

19 Hills M, Armitage P. The two-period cross-over trial. Br J Clin Pharmacol 1979;8:7-20.

20 Mulligan IP, Fraser AG, Tirlapur V, Lewis MJ, Henderson AH. A randomized cross-over study of enalapril in congestive heart failure: haemodynamic and hormonal effects during rest and exercise. Eur $J$ Clin Pharmacol 1988;34:323-31.

21 Francis GS, Goldsmith SR, Ziesche S, Nakajima H, Cohn JN. Relative attenuation of sympathetic drive during exercise in patients with congestive heart failure. J Am Coll Cardiol 1985;5:832-9.

22 Manhem $P$, Lecerof $H$, Hokfelt B. Plasma catecholamine levels in the coronary sinus, the left renal vein and peripheral vessels in healthy males at rest and during exercise. Acta Physiol Scand 1978;104:364-9.

23 Hasking GJ, Esler MD, Jennings GL, Burton D, Johns JA, Korner PI. Norepinephrine spillover to plasma in patients with congestive heart failure: evidence of increased overall and cardiorenal sympathetic nervous activity. Circulation 1986;73:615-21.

24 Yamaguchi N, de Champlain J, Nadeau R. Correlation between the response of the heart to sympathetic stimulation and the release of endogenous catecholamines into the coronary sinus of the dog. Circ Res 1975;36:662-8.

25 Halter JB, Kelly KO, Gould KL. Cardiac uptake and secretion of catecholamines during adrenergic stimulation in vivo. Am J Physiol 1982;243:E52-8.

26 Ekelund L-G. Circulatory and respiratory adaptation during prolonged exercise of moderate intensity in the sitting position. Acta Physiol Scand 1967;69:327-40.

27 Convertino VA, Keil LC, Bernauer EM, Greenleaf JE. Plasma volume, osmolality, vasopressin and renin activity during graded exercise in man. J Appl Physiol 1981;50:123-8.

28 Daly P, Rouleau JL, Cousineau D, Burgess JB, Chatterjee $\mathbf{K}$. Effects of captopril and a combination of hydralazine and isosorbide dinitrate on myocardial sympathetic tone in patients with severe congestive heart failure. Br Heart $J$ 1986;56:152-7.

29 Viquerat CE, Kereiakes D, Morris L, et al. Alterations in left ventricular function, coronary hemodynamics and myocardial catecholamine balance with MDL 17043, a new inotropic vasodilator agent, in patients with severe heart failure. J Am Coll Cardiol 1985;5:326-32.

30 Zimmerman BG. Adrenergic facilitation by angiotensin: does it serve a physiological function? $\mathrm{Clin} \mathrm{Sci}$ 1981;60:343-8.

31 Clough OP, Collis MG, Conway J, Hatton R, Keddie $\mathrm{JR}$. Interactions of angiotensin-converting enzyme inhibitors with the function of the sympathetic nervous system. Am J Cardiol 1982;49:1410-4.

32 Goldsmith SR, Francis GS, Levine BT, Cohn JN. Regional blood flow response to orthostasis in patients with congestive heart failure. J Am Coll Cardiol 1983; 1:1391-5.

33 Cody RJ, Franklin KW, Kluger J, Laragh JH. Mechanisms governing the postural response and baroreceptor abnormalities in chronic congestive heart failure: effects of acute and long-term convertingenzyme inhibition. Circulation 1982;66:135-42.

34 Francis GS, Goldsmith SR, Cohn JN. Relationship of exercise capacity to resting left ventricular performance and basal plasma norepinephrine levels in patients with congestive heart failure. Am Heart J 1982;104:725-31.

35 Cohn JN, Levine TB, Olivari MT, et al. Plasma norepinephrine as a guide to prognosis in patients with chronic congestive heart failure. $N$ Engl $J$ Med 1984:311:819-23.

36 Francis GS. Development of arrhythmias in the patient with congestive heart failure: pathophysiology prevalence and prognosis. Am J Cardiol 1986;57:3B-7B. 